\title{
Effect of Left Ventricular Dyssynchrony on Cardiac Sympathetic Activity in Heart Failure Patients With Wide QRS Duration
}

\author{
Hidekazu Tanaka, MD, PhD; Kazuhiro Tatsumi, MD, PhD; Sei Fujiwara, MD, PhD; \\ Takayuki Tsuji, MD; Akihiro Kaneko, MD; Keiko Ryo, MD; Yuko Fukuda, MD; \\ Kensuke Matsumoto, MD; Mayumi Shigeru, MD; Akihiro Yoshida, MD, PhD; \\ Hiroya Kawai, MD, PhD; Ken-ichi Hirata, MD, PhD
}

\begin{abstract}
Background: Dyssynchrony has various detrimental effects on cardiac function, but its effect on cardiac sympathetic activity is not fully understood.

Methods and Results: We studied 50 heart failure patients who underwent cardiac resynchronization therapy (CRT). Cardiac sympathetic activity was assessed by ${ }^{123}$-metaiodobenzylguanidine (123|-MIBG) scintigraphy as the delayed heart-to-mediastinum ratio (H/M ratio). Echocardiography was performed before and 7 months after CRT, and response was defined as $a \geq 15 \%$ decrease in end-systolic volume. Dyssynchrony was determined by the time difference between the anteroseptal-to-posterior wall using speckle-tracking radial strain $(\geq 130 \mathrm{~ms}$ predefined as significant). $\mathrm{H} / \mathrm{M}$ ratio in patients with dyssynchrony was less than that in patients without dyssynchrony $(1.62 \pm 0.31$ vs. $1.82 \pm 0.36, P<0.05)$, even though ejection fraction was not significantly different $(24 \pm 6 \%$ vs. $25 \pm 7 \%)$. Patients with dyssynchrony and $\mathrm{H} / \mathrm{M}$ ratio $\geq 1.6$ had a higher frequency of response to CRT $(94 \%)$ and favorable long-term outcome over 3.0 years. In contrast, patients without dyssynchrony and $\mathrm{H} / \mathrm{M}$ ratio $<1.6$ were more likely to show a lower frequency of response to CRT $(0 \%)$ and unfavorable long-term outcome after CRT.
\end{abstract}

Conclusions: Dyssynchrony is associated with cardiac sympathetic activity, and ${ }^{123}$-MIBG scintigraphy may be valuable for predicting the response to CRT. (Circ J 2012; 76: 382-389)

Key Words: Asynchrony; Cardiac resynchronization therapy; Echocardiography; Heart failure

$\mathbf{T}$ here is evidence that patients with heart failure (HF) show increased activation of the sympathetic nervous system, as reflected by an increase in plasma norepinephrine levels. In addition, it has been well established that neuronal uptake of norepinephrine is impaired in the failing myocardium. Both the enhanced release of norepinephrine and changes in its cardiac neuronal uptake may be responsible for the observed downregulation of adrenoreceptors in patients with HF. ${ }^{1}$ Metaiodobenzylguanidine (MIBG) is an analog of guanethidine that is taken up by the adrenergic nerve endings and shares common uptake and storage mechanisms with norepinephrine. Its myocardial uptake depends on the integrity of the sympathetic pathway and correlates with the myocardial content of norepinephrine and the degree of myocyte necrosis. Reduced function of the sympathetic nervous system in the heart, as measured by reduced uptake of ${ }^{123} \mathrm{I}-\mathrm{MIBG}$, is an indicator of poor prognosis for patients with HF. ${ }^{1}$

\section{Editorial p 295}

Left ventricular (LV) dyssynchrony has emerged as an important mechanism contributing to the progression of $\mathrm{HF}$ and ventricular remodeling, and appears to play a major pathophysiologic role in HF. ${ }^{2-5}$ Furthermore, it is well known that this dyssynchrony has a detrimental effect on various cardiac functions, such as LV systolic and diastolic function, as well as right ventricular and left atrial function in HF patients with wide QRS duration; however, cardiac resynchronization therapy (CRT) has been shown to have a favorable effect on these affected cardiac functions. ${ }^{1}$ However, the effect of LV dyssynchrony on cardiac sympathetic activity in HF patients with wide QRS duration is not yet fully understood.

Accordingly, our objectives were to evaluate by means of ${ }^{123}$ I-MIBG scintigraphy the effect of LV dyssynchrony on cardiac sympathetic activity of HF patients referred for CRT. We

Received July 19, 2011; revised manuscript received October 3, 2011; accepted October 21, 2011; released online December 1, 2011

Time for primary review: 49 days

Division of Cardiovascular Medicine, Department of Internal Medicine, Kobe University Graduate School of Medicine, Kobe, Japan

Mailing address: Hidekazu Tanaka, MD, PhD, Division of Cardiovascular Medicine, Department of Internal Medicine, Kobe University

Graduate School of Medicine, 7-5-1 Kusunoki-cho, Chuo-ku, Kobe 650-0017, Japan. E-mail: tanakah@med.kobe-u.ac.jp

ISSN-1346-9843 doi:10.1253/circj.CJ-11-0752

All rights are reserved to the Japanese Circulation Society. For permissions, please e-mail: cj@j-circ.or.jp 
also tested the hypothesis that the addition of an assessment of cardiac sympathetic activity by means of ${ }^{123}$ I-MIBG scintigraphy to LV dyssynchrony analysis enhances the capability of the latter to predict the patient's response to CRT.

\section{Methods}

\section{Study Population}

The study group consisted of $54 \mathrm{HF}$ patients undergoing CRT; $4(7 \%)$ patients were excluded from all subsequent analyses because of poor echocardiographic image quality, so eventually $50 \mathrm{HF}$ patients were enrolled in this study (Table 1 ). Their mean age was $68 \pm 11$ years, ejection fraction (EF) was $25 \pm 6 \%$ (all $\leq 35 \%$ ), and QRS duration was $166 \pm 26 \mathrm{~ms}$ (all $\geq 120 \mathrm{~ms}$ ); 18 patients $(36 \%)$ were female, and $13(26 \%)$ had ischemic cardiomyopathy, defined as the presence of $\geq 75 \%$ stenosis of at least 1 major epicardial coronary artery and/or prior coronary revascularization. All patients were classified as New York Heart Association functional class III or IV, 29 (58\%) were diagnosed with sinus rhythm and $4(8 \%)$ with atrial fibrillation. In addition, 17 of the patients (34\%) had previously undergone implantation of a permanent right ventricular (RV) pacing device at least 1 year before enrollment and featured predominantly RV pacing, which was defined as $\geq 90 \%$ paced when the device was interrogated at the time of enrollment. All patients were being treated with optimal pharmacological therapy as long as it was tolerated. Written informed consent was given by all patients.

\section{Echocardiography}

All echocardiographic studies were performed with a commercially available echocardiography system (Vivid 7, GEVingmed, Milwaukee, WI, USA). Patients were studied before

\begin{tabular}{|c|c|}
\hline & $\begin{array}{l}\text { All patients } \\
(n=50)\end{array}$ \\
\hline Age, years & $67 \pm 12$ \\
\hline $\operatorname{Sex}(M / F)$ & $32 / 18$ \\
\hline NYHA functional class III/IV & $44 / 6$ \\
\hline QRS duration, ms & $166 \pm 26$ \\
\hline Rhythm (SR/AF/paced) & 29/4/17 \\
\hline End-diastolic volume, $\mathrm{ml}$ & $168 \pm 26$ \\
\hline End-systolic volume, $\mathrm{ml}$ & $126 \pm 63$ \\
\hline Ejection fraction, \% & $25 \pm 6$ \\
\hline \multicolumn{2}{|l|}{ Heart failure etiology } \\
\hline Ischemic cardiomyopathy & $13(26 \%)$ \\
\hline Nonischemic cardiomyopathy & $37(74 \%)$ \\
\hline \multicolumn{2}{|l|}{ Medication } \\
\hline ACEI/ARB & 47 (94\%) \\
\hline$\beta$-blockers & $45(90 \%)$ \\
\hline Diuretics & $44(88 \%)$ \\
\hline Dyssynchrony by speckle-tracking radial strain, ms & $246 \pm 165$ \\
\hline \multicolumn{2}{|l|}{ Cardiac sympathetic activity } \\
\hline $\mathrm{H} / \mathrm{M}$ ratio & $1.70 \pm 0.34$ \\
\hline Washout ratio & $47 \pm 14$ \\
\hline
\end{tabular}

NYHA, New York Heart Association; SR, sinus rhythm; AF, atrial fibrillation; ACEI, angiotensin-converting enzyme inhibitor; ARB, angiotensin-receptor blocker; $\mathrm{H} / \mathrm{M}$ ratio, heart-to-mediastinum ratio.

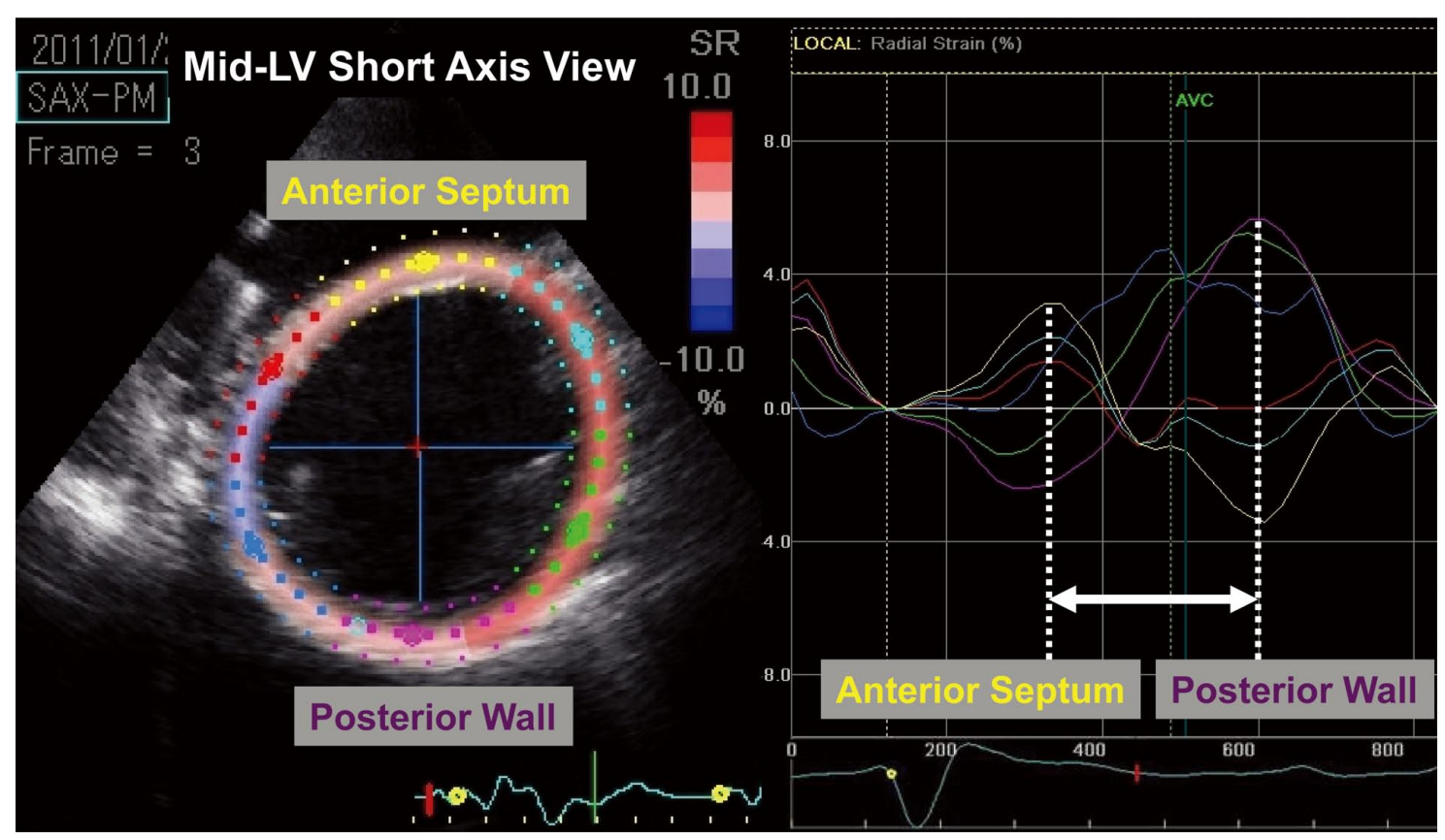

Figure 1. An example of speckle-tracking dyssynchrony analysis based on mid-left ventricular (LV) short-axis views demonstrating radial time-strain curves in a heart failure patient with left bundle-branch block. Dyssynchrony is shown as the difference (white arrow) between the time to peak strain in the anterior septum (yellow curve) and the time to posterior wall peak strain (purple curve). The predefined cut-off of $\geq 130 \mathrm{~ms}$ was considered to indicate significant radial dyssynchrony. 


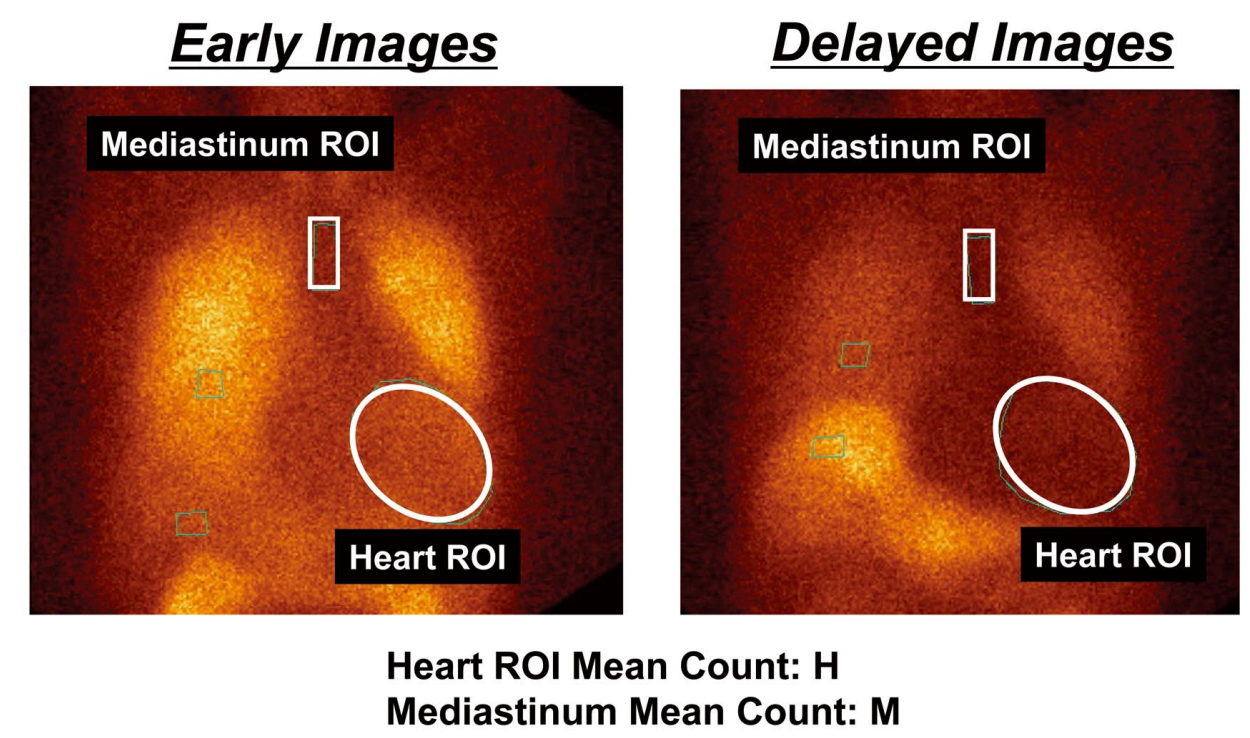

$$
\begin{aligned}
& \text { H/M Ratio }=\text { Delayed H/M } \\
& \text { Washout Rate }=\frac{(\text { Early H }- \text { Early M) }-(\text { Delayed H - Delayed M) }}{\text { Early H - Early M }} \times 100(\%)
\end{aligned}
$$

Figure 2. Calculation of metaiodobenzylguanidine heart-to-mediastinum $(\mathrm{H} / \mathrm{M})$ and washout rates based on an anterior view of the thorax. Regions of interest (ROI) have been drawn over the heart and mediastinum.

and $7 \pm 4$ months after CRT. Digital routine grayscale 2-dimensional cine loops were obtained from 3 consecutive beats with end-expiratory apnea from standard apical (4-chamber, 2chamber, long-axis) and mid-LV short-axis views at a depth of $12-20 \mathrm{~cm}$. Frame rates were $30-100 \mathrm{~Hz}($ mean $65 \pm 15 \mathrm{~Hz}$ ) for grayscale imaging used for speckle-tracking analysis. Sector width was optimized to allow for complete myocardial visualization while maximizing the frame rate. Gain settings were adjusted for routine clinical grayscale 2-dimensional imaging to optimize endocardial definition. LV volumes and EF were assessed by biplane Simpson's rule using manual tracing of digital images. ${ }^{1}$

\section{Assessment of LV Dyssynchrony}

The assessment of LV dyssynchrony by means of speckletracking radial strain using routine grayscale mid-LV shortaxis images was performed offline with dedicated software (EchoPAC version BTO8, GE-Vingmed) as previously described in detail. ${ }^{1}$ Briefly, an end-diastolic circular region of interest (ROI) was traced slightly within the endocardial cavity, using a point-and-click approach with special care taken to adjust tracking of all endocardial segments. A second, larger concentric circle was then automatically generated and manually adjusted near the epicardium. Next, speckle-tracking automatically analyzed frame-by-frame movement of the stable patterns of natural acoustic markers, or speckles, during the cardiac cycle. Measurement of segmental time to peak strain was followed by determination of dyssynchrony by means of speckle-tracking radial strain to measure the time difference between the anteroseptal and posterior walls (Figure 1). A radial speckle-tracking dyssynchrony $\geq 130 \mathrm{~ms}$ was predefined as significant. ${ }^{6-9}$

\section{Assessment of Cardiac Sympathetic Activity}

After thyroid blockade by oral administration of $100 \mathrm{mg}$ of potassium iodide, each patients was intravenously injected with $111 \mathrm{MBq}$ of ${ }^{123} \mathrm{I}-\mathrm{MIBG}$. At $15 \mathrm{~min}$ (early imaging) and $4 \mathrm{~h}$ (delayed imaging) after MIBG administration, a 2 million count planar anterior image of the chest was acquired with a dual-head rotating gamma camera (Vertex Plus, ADAC Laboratories, Milpitas, CA, USA) equipped with a low-energy, general purpose collimator and then stored in a $128 \times 128$ matrix. A ROI was manually drawn over the left ventricle according to the outline of a reference heart image obtained from $99 \mathrm{mTc}$ perfusion images. A rectangular ROI over the upper mediastinum (M) was used as a reference background. Mean counts per pixel were obtained in both the heart $(\mathrm{H})$ and $\mathrm{M}$ for each ROI. To assess MIBG myocardial uptake, the heart-tomediastinum count $(\mathrm{H} / \mathrm{M})$ ratio was first determined from the delayed anterior planar MIBG image (Figure 2). The washout rate was then calculated by the following formula: $\{($ early $\mathrm{H}$-early M) - (delayed $\mathrm{H}$-delayed M) $\} /($ early $\mathrm{H}$-early $\mathbf{M}) \times$ 100(\%), (Figure 2). To assess the association between cardiac sympathetic activity and response to CRT, the patients were divided into 2 prespecified groups, $\mathrm{H} / \mathrm{M}$ ratio $<1.6(\mathrm{n}=19)$ and $\geq 1.6(\mathrm{n}=31$ ), based on the ADMIRE-HF (ADreview Myocardial Imaging for Risk Evaluation in Heart Failure) study. ${ }^{10,11}$

\section{Biventricular Pacemaker Implantation}

A biventricular pacing system was implanted in all patients, with an RV apical lead and an LV lead through the coronary sinus. The LV lead was placed in the lateral vein of 28 patients, the posterolateral vein of 19 patients, and the anterolateral vein of 3 patients. Device implantation was successful in all cases without any major complications. The atrioventricular 


\begin{tabular}{|c|c|c|c|}
\hline & $\begin{array}{l}\text { Patients with } \\
\text { Dyssynchrony } \\
(n=33)\end{array}$ & $\begin{array}{c}\text { Patients without } \\
\text { Dyssynchrony } \\
(n=17)\end{array}$ & Significance \\
\hline Age, years & $68 \pm 11$ & $64 \pm 14$ & NS \\
\hline Sex (Female), n (\%) & $12(36)$ & $6(35)$ & NS \\
\hline QRS duration, ms & $168 \pm 24$ & $163 \pm 29$ & NS \\
\hline Coronary disease, $\mathrm{n}(\%)$ & $8(26)$ & $5(26)$ & NS \\
\hline End-diastolic volume, $\mathrm{ml}$ & $167 \pm 71$ & $169 \pm 75$ & NS \\
\hline End-systolic volume, ml & $128 \pm 63$ & $129 \pm 65$ & NS \\
\hline Ejection fraction, \% & $24 \pm 6$ & $25 \pm 7$ & NS \\
\hline Dyssynchrony by speckle-tracking radial strain, ms & $348 \pm 126$ & $78 \pm 37$ & $<0.001$ \\
\hline
\end{tabular}

(A) H/M Ratio

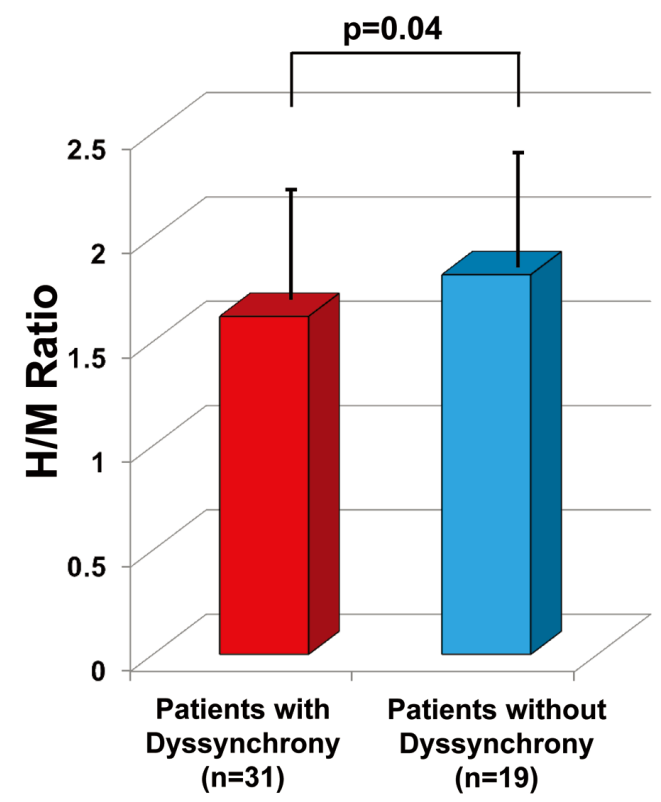

(B) Washout Rate

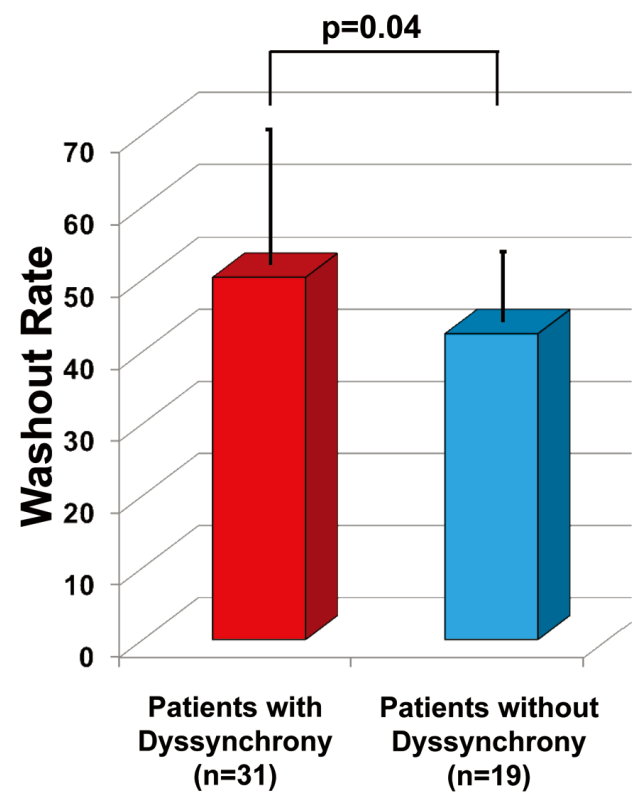

Figure 3. Bar graphs of baseline delayed heart-to-mediastinum $(\mathrm{H} / \mathrm{M})$ ratio $(\mathbf{A})$ and washout rate $(\mathbf{B})$ in patients with and without significant dyssynchrony. The $\mathrm{H} / \mathrm{M}$ ratio of patients with dyssynchrony was significantly lower and the washout rate significantly higher than those of patients without dyssynchrony.

interval was adjusted for optimal diastolic filling by means of Doppler echocardiographic assessment of mitral inflow, ${ }^{12}$ and the interventricular interval was adjusted by means of Doppler echocardiographic assessment of LV outflow $8 \pm 1$ days after implantation. ${ }^{1}$

\section{Definitions of Response and Long-Term Outcome Analysis}

Response to CRT was defined as reverse remodeling detected at 7-month follow-up as a relative reduction $\geq 15 \%$ in endsystolic volume. ${ }^{3,13-15}$ Long-term unfavorable outcome events were prespecified as primary endpoints of death from worsening $\mathrm{HF}$ and hospitalization for deteriorating HF. Long-term follow-up after CRT was tracked over 3.0 years.

\section{Statistical Analysis}

All group data are presented as mean \pm SD and was compared with the 2-tailed Student's t-test for unpaired data between patients with and without dyssynchrony. Proportional differences were evaluated with Fisher's exact test or the chi-square test as appropriate. Differences in the response to CRT between groups were assessed by 1- or 2-way analysis of variance followed by a Tukey multiple comparisons test. Eventfree survival curves were determined according to the KaplanMeier method, with comparisons of cumulative event rates by the log-rank test. For any potential influence of covariates, a Cox proportional hazard model was used. Statistical significance was defined as $\mathrm{P}<0.05$. The authors had full access to the data and take full responsibility for its integrity. All authors have read and agreed to the manuscript as written.

\section{Results}

The baseline clinical and echocardiographic characteristics of the 50 patients are summarized in Table 1 . CRT response, 
(A) LV Dyssynchrony

vs.

H/M Ratio

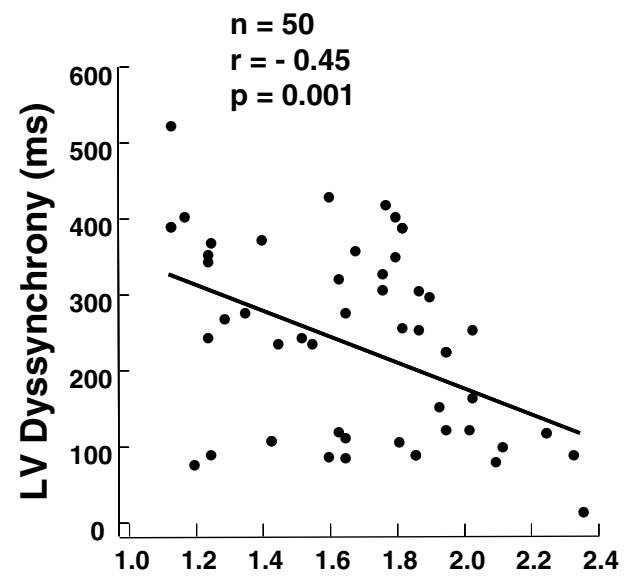

H/M Ratio
(B) LV Dyssynchrony

vs. Washout Rate

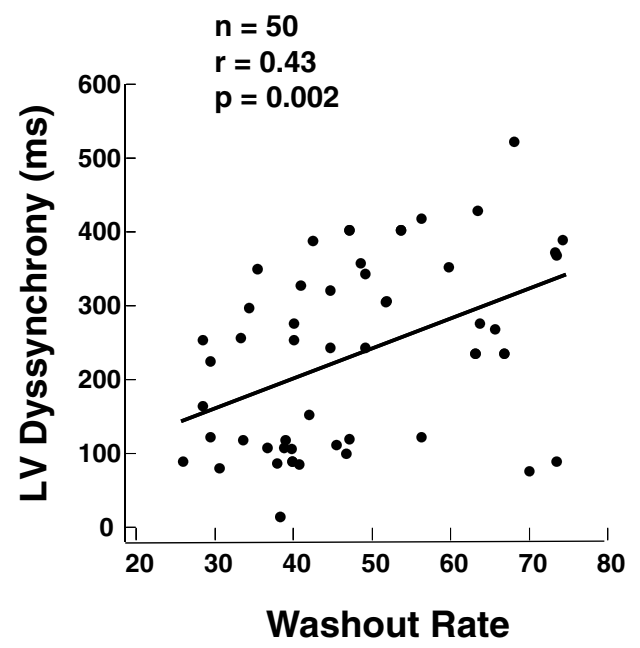

Figure 4. Dot plots of left ventricular (LV) dyssynchrony in relation to delayed heart-to-mediastinum (H/M) ratio (A) and washout rate (B) show a significant correlation.



defined as an $\mathrm{LV}$ functional response in terms of a relative decrease in end-systolic volume $\geq 15 \%$ was observed in 35 patients $(70 \%)$, and the remaining 15 patients $(30 \%)$ were classified as non-responders. The inter- and intra-observer variabilities were $11 \pm 9 \%$ and $9 \pm 7 \%$, respectively, for analysis of LV dyssynchrony from 10 randomly selected patients. The inter- and intra-observer variability was expressed as the absolute difference between the respective measurements divided by their mean value.

Impact of LV Dyssynchrony on Cardiac Sympathetic Activity In total, 33 patients $(66 \%)$ were characterized as exhibiting 


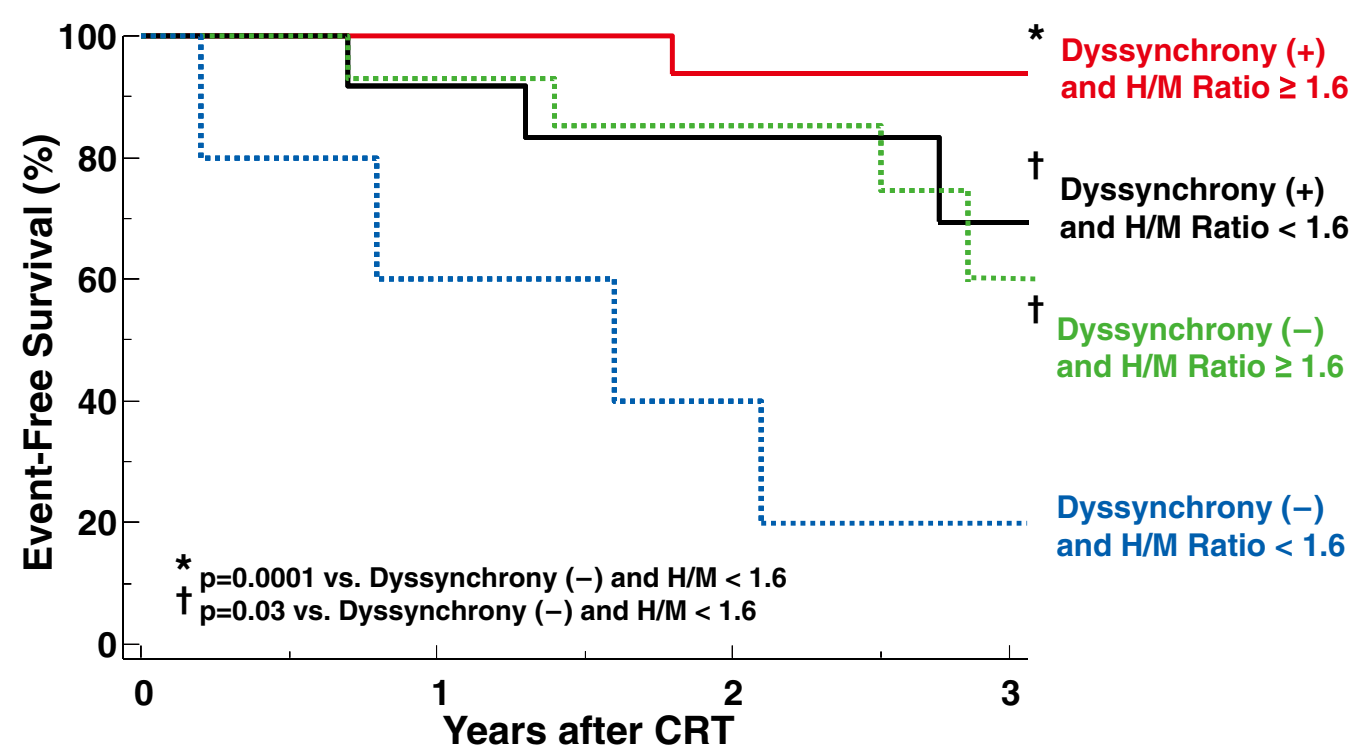

Number at Risk

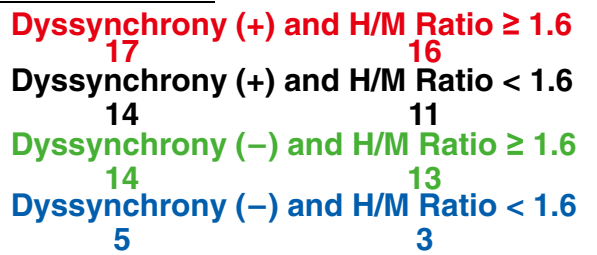

Figure 6. Kaplan-Meier curves of event-free survival after cardiac resynchronization therapy (CRT). Patients with dyssynchrony and a delayed heart-to-mediastinum $(\mathrm{H} / \mathrm{M})$ ratio $\geq 1.6$ had a significantly more favorable long-term outcome after $\mathrm{CRT}$, and patients without dyssynchrony and $\mathrm{H} / \mathrm{M}$ ratio $<1.6$ had a significantly less favorable outcome after $\mathrm{CRT}$ than the other patient subgroups.

significant LV dyssynchrony according to the predefined criteria, and the remaining 17 patients $(34 \%)$ were classified as non-dyssynchronous. The 2 groups showed similar values for mean age, QRS duration, end-diastolic and systolic volumes, $\mathrm{EF}$, prevalence of females and coronary disease. The only difference observed was that, as expected, radial dyssynchrony of patients with dyssynchrony was significantly larger than that of patients without dyssynchrony ( $348 \pm 126$ vs. $78 \pm 37$, $\mathrm{P}<0.0001$, Table 2). HF patients with dyssynchrony showed less cardiac sympathetic activity than did those without dyssynchrony (H/M ratio: $1.62 \pm 0.31$ vs. $1.82 \pm 0.36$, and washout rate: $50 \pm 14$ vs. $42 \pm 12$, both $\mathrm{P}=0.04$ vs. non-dyssynchronous patients), even though EF was not significantly different ( $24 \pm 6 \%$ vs. $25 \pm 7 \%$ ) (Figure 3). Furthermore, baseline LV dyssynchrony significantly correlated with cardiac sympathetic activity ( $\mathrm{H} / \mathrm{M}$ ratio: $\mathrm{r}=-0.45$ and $\mathrm{P}=0.001$, and washout rate: $r=0.43$ and $\mathrm{P}=0.002$, Figure 4 ).

\section{Predictions of Response to CRT Using Combined Method}

There were 17 patients (34\%) with dyssynchrony and H/M ratio $\geq 1$.6. This pattern was associated with a high frequency of LV functional improvement with a response rate of $94 \%$, and the response rate of this group was higher than that of patients with dyssynchrony and H/M ratio <1.6 (94\% vs. 57\%, $\mathrm{P}=0.03$, Figure 5). Patients without dyssynchrony and $\mathrm{H} / \mathrm{M}$ ratio $<1.6$, on the other hand, were more likely to show a lower frequency of LV functional improvement with a response rate of $0 \%$. Furthermore, the response rate of this group was significantly lower than that of the other patient subgroups (Figure 5).

\section{Long-Term Outcome After CRT}

Patients with dyssynchrony and $\mathrm{H} / \mathrm{M}$ ratio $\geq 1.6$ had a significantly more favorable long-term outcome after CRT (Figure 6). Furthermore, patients without dyssynchrony and H/M ratio $<1.6$ had a significantly less favorable outcome after CRT than the other patient subgroups $(\mathrm{P}=0.0001$ vs. patients with dyssynchrony and $\mathrm{H} / \mathrm{M}$ ratio $\geq 1.6, \mathrm{P}=0.03$ vs. patients with dyssynchrony and $\mathrm{H} / \mathrm{M}$ ratio $<1.6$ and patients without dyssynchrony and $\mathrm{H} / \mathrm{M}$ ratio $\geq 1.6$, Figure 6 ).

\section{Discussion}

The findings of our study demonstrated that the cardiac sympathetic activity as assessed by ${ }^{123} \mathrm{I}-\mathrm{MIBG}$ scintigraphy in HF patients with LV dyssynchrony was significantly less than that in HF patients without LV dyssynchrony, even though the EF of the 2 groups was not significantly different. The method of combining LV dyssynchrony by means of speckle-tracking radial strain with $\mathrm{H} / \mathrm{M}$ ratio by means of ${ }^{123} \mathrm{I}-\mathrm{MIBG}$ scintigraphy may thus be more useful for predicting the response to CRT. Our findings further suggest that LV dyssynchrony itself has significant detrimental effects on the cardiac sympathetic activity of HF patients with wide QRS duration, and that the $\mathrm{H} / \mathrm{M}$ ratio may be a valuable additive factor in predicting the response to CRT. 


\section{Cardiac Sympathetic Activity and Patients With HF}

Impaired cardiac sympathetic activity, as assessed by ${ }^{123}$ I-MIBG and independent of its cause, is strongly related to mortality in patients with HF. The prognostic value of ${ }^{123}$ I-MIBG scintigraphy compared with that of other noninvasive cardiac imaging indices was initially studied for patients with either ischemic or idiopathic cardiomyopathy. ${ }^{16-19}$ Of all clinical and imaging variables, these studies, using a delayed $\mathrm{H} / \mathrm{M}$ ratio of 1.20 to identify reduced ${ }^{123}$ I-MIBG uptake, found that only delayed $\mathrm{H} / \mathrm{M}$ ratio and $\mathrm{EF}$ were independent predictors of mortality, with delayed $\mathrm{H} / \mathrm{M}$ ratio being the best predictor of event-free survival. In other large cohorts of patients with HF assessed by ${ }^{123} \mathrm{I}-\mathrm{MIBG}$, a reduced and delayed $\mathrm{H} / \mathrm{M}$ ratio was found to be the most powerful predictor of cardiac mortality. ${ }^{20,21}$ Although a delayed $\mathrm{H} / \mathrm{M}$ ratio $\leq 1.74$, age $>60$ years, a history of myocardial infarction, and New York Heart Association functional class III or IV were identified as strong indicators of poor clinical outcomes, ${ }^{123} \mathrm{I}-\mathrm{MIBG}$ imaging was the most powerful independent long-term prognostic indicator for ischemic or idiopathic cardiomyopathy patients. ${ }^{20}$ Furthermore, Wakabayashi et al reported that a delayed $\mathrm{H} / \mathrm{M}$ ratio was the most powerful independent predictor of cardiac mortality for both groups of patients and superior to an early H/M ratio and washout rate, with an identical threshold for both groups for identifying patients at risk of cardiac death and EF $<50 \% .{ }^{21}$ Recently, ADMIRE-HF provides the first large, prospective confirmation of the strong prognostic value of quantitating cardiac sympathetic activity in HF patients. ${ }^{11}$ They report that preserved cardiac sympathetic activity identifies a very low-risk $\mathrm{HF}$ population, with delayed $\mathrm{H} / \mathrm{M}$ ratio $\geq 1.60$ associated with $1 \% / y e a r$ incidence of cardiac death. In contrast, among the patients with delayed $\mathrm{H} / \mathrm{M}$ ratio $<1.20$, annual rate of cardiac mortality $(9.6 \%)$ was 10 -fold greater.

Some investigators have used ${ }^{123}$ I-MIBG scintigraphy to assess cardiac sympathetic activity in HF patients undergoing $\mathrm{CRT}$. Nishioka et al reported that the $\mathrm{H} / \mathrm{M}$ ratio and washout rate were associated with CRT response, and that the $\mathrm{H} / \mathrm{M}$ ratio was the only independent predictor of CRT response..$^{22}$ Higuchi et al demonstrated that CRT can improve cardiac sympathetic activity as assessed by $\mathrm{H} / \mathrm{M}$ ratio in patients with moderate to severe $\mathrm{HF} .{ }^{23}$ In our study, delayed $\mathrm{H} / \mathrm{M}$ ratio and washout rate as assessed by ${ }^{123}$ I-MIBG scintigraphy were found to be effective methods of evaluating cardiac sympathetic activity, especially when the delayed $\mathrm{H} / \mathrm{M}$ ratio was used to assess CRT response. Cardiac sympathetic activity as assessed by $\mathrm{H} / \mathrm{M}$ ratio and washout rate in $\mathrm{HF}$ patients with LV dyssynchrony was significantly less than that in HF patients without LV dyssynchrony, even though the EF of the 2 groups was not significantly different. LV dyssynchrony itself may have a significantly detrimental effect on cardiac sympathetic activity in $\mathrm{HF}$ patients with wide QRS duration. Though intriguing, the mechanism of the relationship between cardiac sympathetic activity and LV dyssynchrony remains unknown. However, Cha et $\mathrm{al}^{24}$ and Higuchi et $\mathrm{al}^{23}$ reported that cardiac sympathetic activity by means of ${ }^{123}$ I-MIBG scintigraphy was improved in association with improvement of LV dyssynchrony after CRT. Thus, cardiac sympathetic activity and LV dyssynchrony might be related to each other in HF patients.

\section{Clinical Implications}

Although the PROSPECT (Predictors of Responders to Cardiac Resynchronization Therapy) study has suggested that echocardiographic dyssynchrony, such as tissue Doppler velocity, does not have enough predictive value to replace routine selection criteria for $\mathrm{CRT},{ }^{13}$ the utility of speckle-tracking radial strain for identifying responders following CRT has been reported by others. ${ }^{1}$ The STAR (speckle-tracking and resynchronization) study was the recent first prospective multicenter study to investigate the associations of dyssynchrony with EF response and important long-term outcome events after CRT. ${ }^{9}$ They reported that radial strain from short-axis views and transverse strain from apical views were both significantly associated with EF response and long-term survival following CRT. The presence of roughly $30 \%$ non-responders after CRT, as determined with current standard criteria, has a wide variety of causes. Various attempts, especially use of echocardiographic techniques, were made to minimize the number of non-responders after CRT. Although mechanical dyssynchrony has been associated with the response to CRT, other factors, such as myocardial viability or scar burden, LV lead position, and inadequate atrioventricular and ventricular-ventricular optimization, can influence the response to CRT..$^{8,15,25-28}$ The especially important parameters for the lack of response for CRT are absence of mechanical dyssynchrony and impaired myocardial function such as the presence of scar tissue. This means that current identification of responders using timedelay indexes alone is inherently limited, and that combined assessment of LV mechanical dyssynchrony and myocardial function, including myocardial viability or cardiac sympathetic activity, would lead to more accurate prediction than using individual parameters. Thus, the assessment of LV mechanical dyssynchrony with the combination of radial speckletracking strain and delayed $\mathrm{H} / \mathrm{M}$ ratio determined by ${ }^{123}$ I-MIBG scintigraphy may enhance the ability to assess LV mechanical dyssynchrony alone in order to identify patients with a good chance of responding to CRT.

\section{Study Limitations}

This study covered a small number of patients in a single center, so future studies of larger patient populations are necessary to determine the effect of LV dyssynchrony on cardiac sympathetic activity in HF patients with wide QRS duration. One limitation of the speckle-tracking method is endocardial border tracing, which requires care when manually fine-tuning the ROIs to capture the early septal motion followed by later posterior or lateral wall motion in HF patients with wide QRS, and adjustment of QRS width for dyssynchrony analysis before generating and measuring regional strain. Another limitation of this study is that a change in EF and end-systolic volumes was used to define response to CRT and clinical outcome measures such as 6-min walk distance and quality-oflife questionnaires were not systematically performed as part of this study. Finally, we did not assess changes in cardiac sympathetic activity after CRT.

\section{Conclusions}

LV dyssynchrony was found to be associated with cardiac sympathetic activity in HF patients with wide QRS duration. Further, ${ }^{123} \mathrm{I}-\mathrm{MIBG}$ scintigraphy may perform a clinical role in the management of patients undergoing $\mathrm{CRT}$, and the $\mathrm{H} / \mathrm{M}$ ratio may be of a valuable additive factor for the prediction of response to CRT, and thus have potential clinical applications.

\section{Acknowledgments}

The authors are grateful for the support of the entire staff of the echocardiography, electrophysiology, and cardiac imaging laboratories of Kobe University Hospital. 


\section{Disclosure}

There is no ethical problem or conflict of interest with regard to this manuscript.

\section{References}

1. Bohm M, La Rosee K, Schwinger RH, Erdmann E. Evidence for reduction of norepinephrine uptake sites in the failing human heart. J Am Coll Cardiol 1995; 25: 146-153.

2. Abraham WT, Fisher WG, Smith AL, Delurgio DB, Leon AR, Loh $\mathrm{E}$, et al. Cardiac resynchronization in chronic heart failure. $N$ Engl $J$ Med 2002; 346: 1845-1853.

3. Bax JJ, Bleeker GB, Marwick TH, Molhoek SG, Boersma E, Steendijk $\mathrm{P}$, et al. Left ventricular dyssynchrony predicts response and prognosis after cardiac resynchronization therapy. J Am Coll Cardiol 2004; 44: $1834-1840$.

4. St John Sutton MG, Plappert T, Abraham WT, Smith AL, DeLurgio $\mathrm{DB}$, Leon AR, et al. Effect of cardiac resynchronization therapy on left ventricular size and function in chronic heart failure. Circulation 2003; 107: 1985-1990.

5. Yu CM, Fung JW, Zhang Q, Chan CK, Chan YS, Lin H, et al. Tissue Doppler imaging is superior to strain rate imaging and postsystolic shortening on the prediction of reverse remodeling in both ischemic and nonischemic heart failure after cardiac resynchronization therapy. Circulation 2004; 110: 66-73.

6. Gorcsan J 3rd, Abraham T, Agler DA, Bax JJ, Derumeaux G, Grimm RA, et al. Echocardiography for cardiac resynchronization therapy: Recommendations for performance and reporting: A report from the American Society of Echocardiography Dyssynchrony Writing Group endorsed by the Heart Rhythm Society. J Am Soc Echocardiogr 2008; 21: 191-213.

7. Gorcsan J 3rd, Tanabe M, Bleeker GB, Suffoletto MS, Thomas NC, Saba S, et al. Combined longitudinal and radial dyssynchrony predicts ventricular response after resynchronization therapy. J Am Coll Cardiol 2007; 50: 1476-1483.

8. Suffoletto MS, Dohi K, Cannesson M, Saba S, Gorcsan J 3rd. Novel speckle-tracking radial strain from routine black-and-white echocardiographic images to quantify dyssynchrony and predict response to cardiac resynchronization therapy. Circulation 2006; 113: 960-968.

9. Tanaka H, Nesser HJ, Buck T, Oyenuga O, Janosi RA, Winter S, et al. Dyssynchrony by speckle-tracking echocardiography and response to cardiac resynchronization therapy: Results of the speckle tracking and resynchronization (star) study. Eur Heart J 2010; 31: 1690 1700 .

10. Jacobson AF, Lombard J, Banerjee G, Camici PG. ${ }^{123}$ I-MIBG scintigraphy to predict risk for adverse cardiac outcomes in heart failure patients: Design of two prospective multicenter international trials. J Nucl Cardiol 2009; 16: 113-121.

11. Jacobson AF, Senior R, Cerqueira MD, Wong ND, Thomas GS, Lopez VA, et al. Myocardial iodine-123 meta-iodobenzylguanidine imaging and cardiac events in heart failure: Results of the prospective ADMIRE-HF (ADreview Myocardial Imaging for Risk Evaluation in Heart Failure) study. $J$ Am Coll Cardiol 2010; 55: 2212 2221.

12. Ishikawa T, Sumita S, Kimura K, Kikuchi M, Kosuge M, Kuji N, et al. Prediction of optimal atrioventricular delay in patients with implanted DDD pacemakers. Pacing Clin Electrophysiol 1999; 22: $1365-1371$.

13. Chung ES, Leon AR, Tavazzi L, Sun JP, Nihoyannopoulos P, Merlino
J, et al. Results of the predictors of response to CRT (PROSPECT) trial. Circulation 2008; 117: 2608-2616

14. Delgado V, Ypenburg C, van Bommel RJ, Tops LF, Mollema SA, Marsan NA, et al. Assessment of left ventricular dyssynchrony by speckle tracking strain imaging comparison between longitudinal, circumferential, and radial strain in cardiac resynchronization therapy. J Am Coll Cardiol 2008; 51: 1944-1952.

15. Tops LF, Suffoletto MS, Bleeker GB, Boersma E, van der Wall EE, Gorcsan J 3rd, et al. Speckle-tracking radial strain reveals left ventricular dyssynchrony in patients with permanent right ventricular pacing. J Am Coll Cardiol 2007; 50: 1180-1188.

16. Merlet P, Valette H, Dubois-Rande JL, Moyse D, Duboc D, Dove P, et al. Prognostic value of cardiac metaiodobenzylguanidine imaging in patients with heart failure. J Nucl Med 1992; 33: 471-477.

17. Merlet P, Benvenuti C, Moyse D, Pouillart F, Dubois-Rande JL, Duval AM, et al. Prognostic value of MIBG imaging in idiopathic dilated cardiomyopathy. J Nucl Med 1999; 40: 917-923.

18. Cohen-Solal A, Esanu Y, Logeart D, Pessione F, Dubois C, Dreyfus $\mathrm{G}$, et al. Cardiac metaiodobenzylguanidine uptake in patients with moderate chronic heart failure: Relationship with peak oxygen uptake and prognosis. J Am Coll Cardiol 1999; 33: 759-766.

19. Tsutamoto T, Sakai H, Ibe K, Yamaji M, Kawahara C, Nakae I, et al. Effect of atorvastatin vs. rosuvastatin on cardiac sympathetic nerve activity in non-diabetic patients with dilated cardiomyopathy. Circ J 2011; 75: 2160-2166.

20. Nakata T, Miyamoto K, Doi A, Sasao H, Wakabayashi T, Kobayashi $\mathrm{H}$, et al. Cardiac death prediction and impaired cardiac sympathetic innervation assessed by MIBG in patients with failing and nonfailing hearts. J Nucl Cardiol 1998; 5: 579-590.

21. Wakabayashi T, Nakata T, Hashimoto A, Yuda S, Tsuchihashi K, Travin MI, et al. Assessment of underlying etiology and cardiac sympathetic innervation to identify patients at high risk of cardiac death. J Nucl Med 2001; 42: 1757-1767.

22. Nishioka SA, Martinelli Filho M, Brandão SC, Giorgi MC, Vieira ML, Costa R, et al. Cardiac sympathetic activity pre and post resynchronization therapy evaluated by ${ }^{123}$ I-MIBG myocardial scintigraphy. J Nucl Cardiol 2007; 14: 852-859.

23. Higuchi K, Toyama T, Tada H, Naito S, Ohshima S, Kurabayashi M. Usefulness of biventricular pacing to improve cardiac symptoms, exercise capacity and sympathetic nerve activity in patients with moderate to severe chronic heart failure. Circ J 2006; 70: 703-709.

24. Cha YM, Chareonthaitawee P, Dong YX, Kemp BJ, Oh JK, Miyazaki $\mathrm{C}$, et al. Cardiac sympathetic reserve and response to cardiac resynchronization therapy. Circ Heart Fail 2011; 4: 339-344.

25. Adelstein EC, Tanaka H, Soman P, Miske G, Haberman SC, Saba $\mathrm{SF}$, et al. Impact of scar burden by single-photon emission computed tomography myocardial perfusion imaging on patient outcomes following cardiac resynchronization therapy. Eur Heart J 2011; 32: $93-$ 103.

26. Adelstein EC, Saba S. Scar burden by myocardial perfusion imaging predicts echocardiographic response to cardiac resynchronization therapy in ischemic cardiomyopathy. Am Heart J 2007; 153: $105-$ 112.

27. Auricchio A, Prinzen FW. Non-responders to cardiac resynchronization therapy: The magnitude of the problem and the issues. Circ $J$ 2011; 75: 521-527.

28. Strik M, Ploux S, Vernooy K, Prinzen FW. Cardiac resynchronization therapy: Refocus on the electrical substrate. Circ J 2011; 75: $1297-1304$. 